\title{
Can sea urchins beat the heat? Sea urchins, thermal tolerance and climate change
}

\section{Elizabeth Sherman}

The massive die-off of the long-spined sea urchin, Diadema antillarum, a significant reef grazer, in the mid 1980s was followed by phase shifts from coral dominated to macroalgae dominated reefs in the Caribbean. While Diadema populations have recovered in some reefs with concomitant increases in coral cover, the additional threat of increasing temperatures due to global climate change has not been investigated in adult sea urchins. In this study, I measured acute thermal tolerance of $D$. antillarum and that of a sympatric sea urchin not associated with coral cover, Echinometra lucunter, over winter, spring, and summer, thus exposing them to substantial natural thermal variation. Animals were taken from the wild and placed in laboratory tanks in room temperature water $\left(\sim 22^{\circ} \mathrm{C}\right)$ that was then heated at $0.16-0.3{ }^{\circ} \mathrm{C} \mathrm{min}^{-1}$ and the righting behavior of individual sea urchins was recorded. I measured both the temperature at which the animal could no longer right itself $\left(T_{\text {LOR }}\right)$ and the righting time at temperatures below the $T_{\text {LOR. }}$. In all seasons, $D$. antillarum exhibited a higher mean $\mathrm{T}_{\text {LoR }}$ than $E$. lucunter. The mean $\mathrm{T}_{\text {LoR }}$ of each species increased with increasing environmental temperature revealing that both species acclimatize to seasonal changes in temperatures. The righting times of $D$. antillarum were much shorter than those of E. lucunter. The longer relative spine length of Diadema compared to that of Echinometra may contribute to their shorter righting times, but does not explain their higher $\mathrm{T}_{\text {LoR }}$. The thermal safety margin (the difference between the mean collection temperature and the mean $\mathrm{T}_{\text {LoR }}$ ) was between $3.07-3.66^{\circ} \mathrm{C}$ for Echinometra and 3.79$5.67^{\circ} \mathrm{C}$ for Diadema. While these thermal safety margins exceed present day temperatures, they are modest compared to those of temperate marine invertebrates. If sea temperatures increase more rapidly than can be accommodated by the sea urchins (either by genetic adaptation, phenotypic plasticity, or both), this will have important consequences for the structure of coral reefs. 
2 Can sea urchins beat the heat? Sea urchins, thermal tolerance and climate change.

3

4 Elizabeth Sherman

5 Natural Sciences

6 Bennington College

7 Bennington, VT 05201

9 ABSTRACT

10 The massive die-off of the long-spined sea urchin, Diadema antillarum, a significant reef grazer,

11 in the mid 1980s was followed by phase shifts from coral dominated to macroalgae dominated

12 reefs in the Caribbean. While Diadema populations have recovered in some reefs with

13 concomitant increases in coral cover, the additional threat of increasing temperatures due to

14 global climate change has not been investigated in adult sea urchins. In this study, I measured

15 acute thermal tolerance of $D$. antillarum and that of a sympatric sea urchin not associated with

16 coral cover, Echinometra lucunter, over winter, spring, and summer, thus exposing them to

17 substantial natural thermal variation. Animals were taken from the wild and placed in laboratory

18 tanks in room temperature water $\left(\sim 22^{\circ} \mathrm{C}\right)$ that was then heated at $0.16-0.3{ }^{\circ} \mathrm{C} \mathrm{min}{ }^{-1}$ and the

19 righting behavior of individual sea urchins was recorded. I measured both the temperature at

20 which the animal could no longer right itself $\left(\mathrm{T}_{\mathrm{LoR}}\right)$ and the righting time at temperatures below

21 the $\mathrm{T}_{\mathrm{LoR}}$. In all seasons, D. antillarum exhibited a higher mean $\mathrm{T}_{\mathrm{LoR}}$ than E. lucunter. The mean

$22 \mathrm{~T}_{\mathrm{LoR}}$ of each species increased with increasing environmental temperature revealing that both

23 species acclimatize to seasonal changes in temperatures. The righting times of D. antillarum

24 were much shorter than those of E. lucunter. The longer relative spine length of Diadema 
compared to that of Echinometra may contribute to their shorter righting times, but does not

26 explain their higher $\mathrm{T}_{\text {LoR }}$. The thermal safety margin (the difference between the mean collection

27 temperature and the mean $\mathrm{T}_{\mathrm{LoR}}$ ) was between $3.07-3.66^{\circ} \mathrm{C}$ for Echinometra and $3.79-5.67^{\circ} \mathrm{C}$ for

28 Diadema. While these thermal safety margins exceed present day temperatures, they are modest

29 compared to those of temperate marine invertebrates. If sea temperatures increase more rapidly

30 than can be accommodated by the sea urchins (either by genetic adaptation, phenotypic

31 plasticity, or both), this will have important consequences for the structure of coral reefs.

\section{INTRODUCTION}

34 Adult sea urchins are grazers and have been dominant herbivores in many Caribbean reefs for 35 decades and perhaps millennia (Lessios, Garrido \& Kessing, 2001; Levitan, Edmunds \& Levitan, 36 2014). A convincing and well-documented example of their influence on coral reef community

37 structure occurred in the mid 1980's when Caribbean sea urchin populations of Diadema 38 antillarum experienced a massive die-off. The subsequent overgrowth of macroalgae resulted in

39 decreased coral cover and recruitment and concomitant biodiversity losses from which reefs have

40 not fully recovered (Jackson, 2001; Levitan, Edmunds \& Levitan, 2014; Miller et al., 2009).

41 Nevertheless, rebounds in Diadema populations in certain Caribbean locations are correlated

42 with greater coral recruitment and coral growth (Edmunds \& Carpenter, 2001; Knowlton, 2001;

43 Carpenter \& Edmunds, 2006; Idjadi, Haring \& Precht, 2010), which might presage an increase in

44 fish diversity (Rogers et al, 2014). The proximate cause of the Diadema die-off was likely a

45 disease agent that has never been identified (Beck, Miller \& Ebersole, 2014), but additional

46 environmental stressors such as increasing ocean temperature due to global climate change may 
47 also be deleterious for marine ectotherms such as echinoids particularly in intertidal and subtidal 48 tropical habitats (Nguyen et al. 2010).

49 Tropical sea temperatures are predicted to increase by as much as $4.8^{\circ} \mathrm{C}$ by the end of this 50 century (IPCC, 2014). Threshold temperatures for coral bleaching have been evaluated in light of 51 those predictions (e.g. Tolleter et al., 2013; Hoegh-Guldberg, 1999; Donner, 2011). There is also 52 a growing literature on the effects of anticipated future temperature increases on fertilization and 53 early development of echinoids (Brennand et al., 2010; Byrne, 2011; Byrne et al., 2009; Sewell $54 \&$ Young, 1999). The few previous studies of thermal tolerance in adult sea urchins, however, 55 did not evaluate results in the context of global climate change (Lawrence, 1973; Lawrence \& 56 Cowell, 1996; Ubaldo, Uy \& Dy, 2007). Moreover, no thermal tolerance data exist for the 57 Caribbean keystone species, Diadema antillarum. Additionally, characterizing the thermal 58 tolerance of sea urchins might permit predictions about changes in their geographic ranges (Ling 59 et al., 2009).

60 I studied the thermal tolerance of the long-spined sea urchin, Diadema antillarum, and 61 compared it to the sympatric rock-boring sea urchin, Echinometra lucunter, which, unlike 62 Diadema, is not associated with low macroalgal cover (Furman \& Heck, Jr., 2009). My study 63 site was in Grand Cayman, British West Indies, on the western side of the island within the 64 Marine Protected Area (McCoy, Dromard \& Turner, 2009). I collected urchins from depths 65 ranging from just below the surface to $3 \mathrm{~m}$. The animals were collected opportunistically based 66 on their accessibility and whether they would be too large to accommodate in the lab or too small 67 to be adults. Both species occurred at depths of $3 \mathrm{~m}$, but only Echinometra occurred at the 68 shallowest depths; I never found Diadema less than about $30 \mathrm{~cm}$ below the water surface. I 69 would expect therefore that Echinometra might be exposed to higher daily temperatures than 
70 Diadema and thus might have a higher thermal tolerance (Nguyen et al., 2011). On the other

71 hand, the rock boring behavior of Echinometra might mitigate temperature fluctuations given

72 that they were always wedged into crevices during the day, while I found Diadema in exposed

73 areas of the reef during the day.

74 I measured the thermal tolerance of individuals of these species over three seasons, and

75 thus three different temperature regimes to determine if they acclimatized to changes in

76 environmental water temperature. Finally, I measured variation in thermal tolerance among

77 individuals of the two species as such variation might serve as a substrate for natural selection in

78 warming seas.

80 MATERIALS AND METHODS

\section{Collection Site}

82 Sea urchins of both Diadema antillarum and Echinometra lucunter were collected (under a

83 permit granted by the Cayman Islands Department of Environment), by snorkeling in a small

84 rectangular inlet south of George Town harbour, Grand Cayman, located at 19¹6 $42.69^{\prime \prime} \mathrm{N}$,

$8581^{\circ} 23^{\prime} 34.79$ ” W, (in the Marine Protected Area between study sites GCM9 and GCM5 of

86 McCoy, Dromard \& Turner, 2009). The inlet was roughly $36 \mathrm{~m}$ long x $14 \mathrm{~m}$ wide with a gently

87 sloped floor that reached the more open sea at a depth of about $3 \mathrm{~m}$. The walls of the inlet were

88 composed of eroded ironshore (Logan, 2013), with many cracks and crevices in which sea

89 urchins, particularly E. lucunter, were found (Fig 1a). The floor of the inlet was coral rubble and

90 sand where patches of D. antillarum were found (Fig. 1b).

91 Both species were collected in the afternoon during the winter (February, 2013), spring

92 (May, 2010) and summer (August, 2011) in order to assess the extent of acclimatization of 
93 thermal tolerance among animals that had likely been exposed to substantial inter-seasonal

94 temperature variation. I measured the temperature at both shallow $(10 \mathrm{~cm}$ below the surface) and

95 deeper collection sites ( $2.5 \mathrm{~m}$ below the surface) during each collection visit using a Fisher

96 Scientific Precision Thermometer, (accurate to $0.01^{\circ} \mathrm{C}$ ) or a mercury thermometer (accurate to

$970.1^{\circ} \mathrm{C}$ ). Unexpectedly, there was no temperature difference with depth. I confirmed this by

98 collecting temperatures at 15 -minute intervals for several days to a full week in both shallow and

99 deeper collection sites (Onset HOBO temperature probes and data logger). The shallow site was

100 not a sequestered intertidal pool but rather was flushed with seawater constantly, perhaps

101 accounting for the absence of a temperature differential between shallow and deeper sites.

102 Therefore, collection temperatures are reported as the combined mean from the shallow and deep

103 sites for each season.

104 Animal maintenance in the laboratory

105 Animals were maintained in a laboratory at the Cayman Islands Department of Environment

106 building in George Town, Grand Cayman. Between 4-8 sea urchins of either species were

107 maintained in a 501 tank of aerated seawater at room temperature $\left(22.5 \pm 0.7^{\circ} \mathrm{C}\right)$ and under

108 natural light. All animals were tested within 3 days of collection. Animals were not fed while in

109 the laboratory.

\section{Measures of thermal tolerance: righting time and critical thermal maximum}

111 I measured both the righting time as temperature was increased and the temperature at which

112 each sea urchin could no longer right itself $\left(\mathrm{T}_{\text {Lor }}\right)$ after inversion as indicators of thermal

113 tolerance. The latter measurement is repeatable and indicates the temperature at which the

114 neuromuscular system of the animal no longer has sufficient integrity to mediate righting. It has 
115 been a reliable indicator of stress in many animal species including echinoids (Lawrence \&

116 Cowell, 1996; Challener \& McClintock, 2013; Ubaldo, Uy \& Dy, 2007).

117 Each sea urchin was tested individually and placed in a tank with a volume of room

118 temperature aerated seawater sufficient to cover the urchin and provide room for me to invert the

119 animal. The experimental substrate was smooth without sand or gravel. The water was aerated

120 through the entire experiment, which also mixed the water as it was heated. At the beginning of

121 each trial (in room temperature water), the sea urchin was placed on its aboral surface (using

122 wooden spatulas) and the time for the animal to right itself completely (its oral surface

123 contacting and parallel to the tank bottom) was recorded. The testing tanks were large and could

124 not be heated sufficiently using available heaters. In order to heat the water, therefore, small

125 volumes of test water were removed (without disturbing the test animal) and were replaced by

126 comparable volumes of aerated and heated water from a different tank (with a smaller volume

127 that was easier to heat). With practice following pilot studies, I was able to reliably increase the

128 water temperature in the test tank at a rate of $0.16-0.3{ }^{\circ} \mathrm{C} \mathrm{min}^{-1}$. I constantly mixed the water in

129 the test tank with a paddle and measured the water temperature with a Fisher Scientific Precision

130 Thermometer, (accurate to $0.01^{\circ} \mathrm{C}$ ) which remained in the test tank. As the water was heated, the

131 animal was inverted periodically (roughly once for each degree increase, and more frequently as

132 loss of righting ability approached) and the righting time was recorded. The end point of the loss

133 of righting was taken as the temperature at which the animal no longer could right itself (within

13415 minutes of inversion), and was designated the $T_{\text {LoR. }}$. The animals were not dead at loss of

135 righting, as they continued to move their spines and mouthparts. Moreover, after the $\mathrm{T}_{\mathrm{LoR}}$ was

136 noted, each animal was immediately placed in room temperature seawater after which

137 coordinated movement was restored. The sea urchins did not appear to habituate to inversion as 
138 the righting times for an individual did not get progressively longer through the experiment until

$139 \mathrm{~T}_{\mathrm{LoR}}$ was imminent.

140 In order to determine if age (size) influenced the $\mathrm{T}_{\mathrm{LoR}}$, I measured the test diameter of

141 each sea urchin following the experiment with vernier calipers (to the nearest $\mathrm{mm}$ ). If the test

142 shape of the sea urchin was not a circle, I measured the major axis. D. antillarum have spines of

143 very different length while those of $E$. lucunter are more similar in length and this difference in

144 morphology appeared to affect how the animals maneuvered themselves during righting.

145 Therefore, I also measured the length of a spine that appeared to be among the longest on each

146 animal.

147 In other studies (e.g. Lawrence, 1973), inverted animals were placed in water of

148 particular temperatures and then righting time was measured, whereas in this study, the water

149 was heated until the animal could no longer right itself. Heating rates affect the thermal tolerance

150 of many marine invertebrates (Nguyen et al., 2011). The data in the present study reflect acute

151 responses to increasing temperatures of animals taken from the wild that had been acclimatized

152 to winter, spring, or summer temperatures.

153 The mean collection temperatures $( \pm \mathrm{SEM})$ were $27.2^{\circ} \mathrm{C}( \pm 0.12)$ in February, $28.8^{\circ} \mathrm{C}$

$154( \pm 0.13)$ in May, and $30.4^{\circ} \mathrm{C}( \pm 0.09)$. In Figure 2, I compared the mean collection temperatures of

155 this study with data from the Cayman Islands provided by the National Oceanic and Atmospheric

156 Administration (NOAA) Coral Reef Watch (2000, sampled twice weekly). I used NOAA data

157 from 2010-2013 in the months of February, May and August to determine if my collection

158 temperatures were representative of typical seasonal Cayman Islands reef water temperatures. In

159 both data sets, there are comparable changes in mean temperatures with season. Moreover, the

160 temperatures I measured are consistent with those reported in the NOAA data albeit slightly 
161 higher by $0.58-0.8^{\circ} \mathrm{C}$. I collected temperatures during the day while the NOAA data were

162 collected at night, accounting for the slightly greater temperatures reported here (Fig. 2).

163 Statistical analyses

164 To determine if there were differences between species and among collection temperatures in

165 loss of righting temperatures $\left(\mathrm{T}_{\mathrm{LoR}}\right)$, I performed a two-way ANOVA with species and collection

166 temperatures as fixed factors and $T_{\text {LoR }}$ as the dependent variable. At temperatures below the $T_{L o R}$

$167\left(\leq 30.9^{\circ} \mathrm{C}\right) \mathrm{I}$ analyzed whether species and collection temperatures affected righting times using a

168 multiple regression analysis. I also compared the ratio of the length of a long spine to test

169 diameter between the two species using the Student's t-test. Finally, I performed linear

170 regression analyses to determine if size (test diameter) was a predictor of $\mathrm{T}_{\mathrm{LoR}}$ for each species in

171 each season.

172

\section{RESULTS}

174 The mean temperatures for loss of righting $\left(T_{L o R}\right)$ of both species were greater than the collection

175 temperatures and increased with increasing collection temperature, so that those collected in the

176 winter had the lowest thermal tolerance and the summer collected sea urchins had the highest

177 (Fig. 3). D. antillarum lost righting ability at significantly higher temperatures than E. lucunter

178 at all collection temperatures (Fig. 3). The 2-way ANOVA showed that both species $(\mathrm{p}<0.0001)$

179 and collection temperature $(\mathrm{p}<0.0001)$ were significant predictors of $\mathrm{T}_{\mathrm{LoR}}$ but their interaction

180 was not $(\mathrm{p}=0.12)$. The difference between the mean collection temperature and the mean $\mathrm{T}_{\mathrm{LoR}}$,

181 which can be thought of as the thermal safety margin (Nguyen et al., 2011), was more than $3^{\circ} \mathrm{C}$

182 for E. lucunter in all seasons (Table 1). The thermal safety margin of $D$. antillarum was almost

$1836^{\circ} \mathrm{C}$ in winter and summer but only $3.79^{\circ} \mathrm{C}$ in the spring. Thus, the $\mathrm{T}_{\mathrm{LoR}}$ of $E$. lucunter increased 
184 roughly linearly with seasonal temperature. However, the $\mathrm{T}_{\mathrm{LoR}}$ of $D$. antillarum, while greater

185 than that of E. lucunter, did not change from winter to spring, although it was higher in the 186 summer (Fig. 3; Table 1).

There was variation in $\mathrm{T}_{\text {LoR }}$ within both species (Table 2). Diadema exhibited the largest range in $\mathrm{T}_{\mathrm{LoR}}$ during the winter $\left(5.3^{\circ} \mathrm{C}\right)$ while Echinometra exhibited the largest range in $\mathrm{T}_{\mathrm{LoR}}$ during the summer $\left(3.6^{\circ} \mathrm{C}\right)$.

The rock boring E. lucunter took longer to right themselves compared to D. antillarum at

191 all temperatures below the $\mathrm{T}_{\mathrm{LOR}}(\mathrm{p}<0.0001$; Fig. 4). Collection temperature also affected the

192 righting times below the $\mathrm{T}_{\mathrm{LoR}}(\mathrm{p}=0.025)$, likely due to the slower righting times of winter collected Diadema. The temperature at which the sea urchins were tested did not have a

194 significant effect on righting times ( $\mathrm{p}=0.561)$. Typically, the E. lucunter that righted themselves took between 100-240 seconds while $D$. antillarum righted themselves in less than 100 seconds.

196 I have provided video examples of the righting behavior of both species in the supplementary 197 material.

198 When the long-spined sea urchin righted itself, it appeared to rely on the levering action 199 of the longer spines, which exceeded the diameter of the test, to rock the animal onto its side.

200 The rock boring sea urchin, on the other hand, used its tube feet rather than its spines, which

201 were shorter than the test diameter, to push and pull itself onto its side. The greater mean ratio of 202 the length of a spine to test diameter in Diadema $(1.38 \pm 0.1)$ compared to Echinometra $(0.78 \pm$ $2030.04)$ is illustrated in Figure $5(\mathrm{p}<0.0001)$.

$204 \mathrm{~T}_{\mathrm{LoR}}$ did not vary with test diameter in either species (Fig. 6; for D. antillarum, p values 205 for all seasons $>0.4$; for $E$. lucunter, $\mathrm{p}$ values for all seasons $>0.1$ ). Although the test diameters 206 overlapped between the two species, on average, Diadema were larger than Echinometra. 
208 DISCUSSION

209 Temperature affects the physiological responses of tropical marine animals more than other

210 possible stressors of climate change (Przeslawski et al., 2008). Both species of sea urchin in this

211 study exhibited acclimatization to seasonal temperature changes in experiments measuring acute

212 thermal tolerance (Fig. 3), their $\mathrm{T}_{\mathrm{LoR}}$ increasing with increases in environmental temperature.

213 Nevertheless, like other tropical animals, the safety margin of thermal tolerance above ambient

214 temperatures $\left(\sim 3-6^{\circ} \mathrm{C}\right.$, Table 1$)$ was small compared to that of temperate animals (Przeslawski et

215 al., 2008; Nguyen et al 2011). It is possible that the thermal safety margins of the sea urchins

216 would be different with a slower rather than acute temperature increase that would more closely

217 resemble natural temperature changes. However, Nguyen et al. (2011) demonstrated that

218 subtidal tropical animals exhibited lower thermal tolerances when heated at slower rates. So the

219 thermal tolerances reported in this study likely represent the highest tolerances that these animals

220 can exhibit given how rapidly they were heated. Nevertheless, different thermal tolerance end

221 points and different heating rates (e.g. Hernández et al, 2004; Nguyen et al, 2011) make

222 comparisons of particular thermal tolerances across different studies difficult.

223

Diadema exhibited the largest range in $\mathrm{T}_{\mathrm{LOR}}$ during the winter and the smallest range

224 during the summer, while Echinometra showed the opposite tendency, with the largest range in

$225 \mathrm{~T}_{\mathrm{LoR}}$ in the summer (Table 2). These variations in thermal tolerance suggest some capacity for

226 evolutionary adaptation to temperature changes if the variation among adults has a genetic

227 component. The sea urchins also exhibited variation in righting times at temperatures below the

$228 \mathrm{~T}_{\mathrm{LoR}}$ (Fig. 4) and this variation may affect their daily movements such as foraging, in warming

229 seas. Like other benthic invertebrates, sea urchins have pelagic larvae, which may be exposed to 
230 different conditions from those of adults. Since larvae disperse widely (Lessios, 1988), urchins

231 have the potential to establish in new areas, facilitating range changes in response to global

232 climate change (Ling et al, 2009; Przeslawski et al., 2008). Alternatively, if sea urchins cannot

233 adapt to the rapid changes in their environments, local populations may become extinct.

234 The proximate causes of interspecific differences in thermal tolerance responses are

235 unclear (Fig. 3 and Fig. 4). Both species were exposed to similar daily and seasonal temperature

236 variations. One possible proximate cause of the faster righting time of Diadema is the difference

237 in spine length relative to test size (Fig. 5). The Diadema used their relatively long aboral spines

238 as levers to topple them over when righting. The Echinometra, having much shorter spines, used

239 their tube feet to right themselves, which was a more time consuming process. The different

240 uses of spines versus tube feet have been reported in other motor behaviors of sea urchins as well

241 by Domenici, González-Calderón, \& Ferrari (2003). They, however, found that size affected

242 motor behavior on vertical and horizontal surfaces, whereas size had no effect on righting

243 behavior in my study (Fig. 6), nor did it affect thermal safety margins in other tropical

244 ectotherms (Nguyen et al, 2011). The different relative length of spines might explain why

245 Echinometra took longer to right themselves at temperatures below $\mathrm{T}_{\text {LoR. }}$. However, it would not

246 account for the lower $\mathrm{T}_{\text {LoR }}$ (Fig. 3) and smaller thermal safety margin (Table 1) of Echinometra.

247 Righting behavior may have more survival value to Diadema than Echinometra. Both species

248 forage at night (Hendler et al., 1995) but only Diadema were found in the open during the day

249 and I have observed fish flipping them over in order to eat them. The rock-boring urchins, on the

250 other hand, as the name implies, are jammed into crevices and typically not found in the open

251 during the day. At night, the temperature can fall by as much as $1{ }^{\circ} \mathrm{C}$ in the summer (unpublished 
252 data) so Echinometra are less likely to be exposed and vulnerable during higher daytime

253 temperatures.

254 Phase shifts from coral to macroalgal dominance following the Diadema antillarum die

255 off in the Caribbean have been widely reported (e.g. Jackson, 2001, Lessios, 1988). There

256 appears to be great regional variation in the recovery of different populations of these sea urchins

257 (Carpenter \& Edmunds, 2006; Levitan, Edmunds \& Levitan, 2014; Miller et al., 2009). Regions

258 in which Diadema are increasing in number are correlated with increases in coral settling and

259 cover (Carpenter \& Edmunds, 2006; Knowlton, 2001; Furman \& Heck, Jr. 2009; Idjadi, Haring

260 \& Precht, 2010). Unlike D. antillarum populations, E. lucunter populations have been relatively

261 stable throughout the Caribbean and have not been associated with changes in coral density

262 (Furman \& Heck, Jr., 2009). Both species of sea urchins in the present study were collected

263 from local populations in a small area in a Grand Cayman reef. It is not clear, therefore, how

264 representative their thermal tolerance responses are compared to sea urchins from other areas.

265 Both species demonstrated a significant capacity to acclimatize to different seasonal

266 temperatures, which may serve them well as sea temperatures increase. Nguyen et al. (2011)

267 suggested that temperature increases as low as $2-3^{\circ} \mathrm{C}$ above present levels are likely to be

268 stressful to tropical marine ectotherms. The sea urchins in this study, however, appear to be able

269 to tolerate such changes. Additional studies are required to determine the capacity of sea urchins

270 to adapt to acute versus long-term thermal stress and the costs of such adaptation as global sea

271 temperatures increase.

272

273 CONCLUSION 
274 Tropical sea temperatures may increase by as much as $4.8^{\circ} \mathrm{C}$ by the end of this century (IPCC,

275 2014). It remains to be seen if sea urchins will be able to adapt to these higher temperatures.

276 Moreover, other stressors (such as ocean acidification, infectious disease, runoff from land) are

277 likely to have synergistically deleterious effects on tropical marine ectotherms (Przeslawski et

278 al., 2008). Populations may adapt to higher sea temperatures by natural selection given the

279 within season variation in thermal tolerance exhibited by sea urchins in this study. The sea

280 urchins revealed at least seasonal plasticity in their capacity to acclimatize to different

281 temperatures. Alternatively, if sea temperatures increase more rapidly than can be

282 accommodated by sea urchins, local populations may become extinct. Changes in the number of

283 Diadema antillarum, in particular, will have important consequences for the structure of coral

284 reefs.

285

286 ADDITIONAL INFORMATION AND DECLARATIONS

287 Competing interests

288 The author declares there are no competing interests.

289 Funding

290 This work was supported by grants from Bennington College.

291 Author contributions

292 The author conceived, designed, conducted the experiments, analyzed the results, and prepared

293 the manuscript.

294 Acknowledgements

295 This work was supported in large part by the Cayman Islands Department of Environment,

296 which supplied lab space, technical assistance, and sea urchin collecting permits. I am grateful 
297 to this fine institution directed by Gina Ebanks-Petrie. Particular thanks go to staff scientists Tim 298 Austin, John Bothwell, Gene Parsons, and James Gibb. Nancy Knowlton and Jeremy Jackson 299 discussed this work with me and I appreciate their insights. Thanks to Kathryn Montavan for 300 help with statistical analyses. Kerry Woods provided valuable comments on a prior version of

301 this manuscript. I am grateful to the PeerJ reviewers whose suggestions and comments enhanced

302 the quality of this paper. I would also like to thank Dusty Norman of DNS Diving for technical

303 assistance. Finally, thanks go to the people who helped collect sea urchins: Amie McClellan,

304 Terry Creach, Katie Alpers.

305 Supplemental information

306 Videos of righting behavior (at 2x normal speed) in Diadema antillarum and Echinometra

307 lucunter.

308 REFERENCES

310 Beck G, Miller R, Ebersole R. 2014. Mass mortality and slow recovery of Diadema antillarum:

311 Could compromised immunity be a factor? Marine Biology 161: 1001-1013.

313 Brennand H, Soars N, Dworjanyn S, Davis A, Byrne M. 2010. Impact of ocean warming and

314 ocean acidification on larval development and calcification in the sea urchin Tripneustes gratilla.

315 PLoS One 5: e11372.

316 Byrne M. 2011. Impact of ocean warming and ocean acidification on marine invertebrate life

317 history stages: Vulnerabilities and potential for persistence in a changing ocean. Oceanography

318 and Marine Biology: An Annual Review 49: 1-42.

319 Byrne M, Ho M, Selvakumaraswamy P, Nguyen HD, Dworjanyn SA, Davis AR. 2009. 
320 Temperature, but not $\mathrm{pH}$, compromises sea urchin fertilization and early development under

321 near-future climate change scenarios. Proceedings of the Royal Society B 276: 1883-1888.

322 Carpenter RC, Edmunds PJ. 2006. Local and regional scale recovery of Diadema promotes

323 recruitment of scleractinian corals. Ecology Letters 9: 271-280.

324 Challener RC, McClintock JB. 2013. Exposure to extreme hypercapnia under laboratory

325 conditions does not impact righting and covering behavior of juveniles of the common sea urchin

326 Lytechinus variegatus. Marine and Freshwater Behaviour and Physiology 46: 191-199.

327 Domenici P, González-Calderón D, Ferrari RS. 2003. Locomotor performance in the sea

328 urchin Paracentrotus lividus. Journal of the Marine Biological Association of the U.K. 83: 285-

329292.

330 Donner SD. 2011. An evaluation of the effect of recent temperature variability on the prediction

331 of coral bleaching events. Ecological Applications 21: 1718-1730.

332 Edmunds PJ, Carpenter RC. 2001. Recovery of Diadema antillarum reduces macroalgal cover

333 and increases abundance of juvenile corals on a Caribbean reef. Proceedings of the National

334 Academy of Sciences 98: 5067-5071.

335 Furman B, Heck KL, Jr. 2009. Differential impacts of echinoid grazers on coral recruitment.

336 Bulletin of Marine Science 85: 121-132.

337 Hendler G, Miller J, Pawson G, Kier P. 1995. Sea stars, sea urchins, and allies: echinoderms

338 of Florida and the Caribbean. Washington: Smithsonian Institution Press.

339 Hernández M, Buckle F, Guisado C, Barón B, Estavillo N. 2004. Critical thermal maximum 
340 and osmotic pressure of the red sea urchin Strongylocentrotus franciscanus acclimated at

341 different temperatures. Journal of Thermal Biology 29: 231-236.

342 Hoegh-Guldberg O. 1999. Climate change, coral bleaching and the future of the world's coral

343 reefs. Marine Freshwater Research 50: 839-866.

344 Idjadi J, Haring R, Precht W. 2010. Recovery of the sea urchin Diadema antillarum promotes

345 scleractinian coral growth and survivorship on shallow Jamaican reefs. Marine Ecology Progress

346 Series 403:91-100.

347 IPCC. 2014. Climate change 2014: Synthesis Report. Contribution of Working Groups I, II, and

348 III to the Fifth Assessment Report of the Intergovernmental Panel on Climate Change [Core

349 Writing Team, R. K Pachauri and L. A. Meyer (eds.)]. IPCC, Geneva, Switzerland, 151 pp.

350 Jackson JBC. 2001. What was natural in the coastal oceans? Proceedings of the National

351 Academy of Sciences 98: 5411-5418.

352 Knowlton N. 2001. Sea urchin recovery from mass mortality: new hope for Caribbean coral 353 reefs? Proceedings of the National Academy of Sciences 98: 4822-4824.

354 Lawrence JM. 1973. Temperature tolerances of tropical shallow-water echinoids

355 (Echinodermata) at Elat (Red Sea). Israel Journal of Zoology 22: 143-150.

356 Lawrence JM, Cowell BC. 1996. The righting response as an indication of stress in Stichaster

357 striatus (Echinodermata, Asteroid). Marine and Freshwater Behaviour and Physiology 27: 239358248.

359 Lessios HA. 1988. Mass mortality of Diadema antillarum in the Caribbean: what have we 
360 learned? Annual Review of Ecology and Systematics 19: 371-393.

361 Lessios HA, Garrido MJ, Kessing, BD. 2001. Demographic history of Diadema antillarum, a

362 keystone herbivore on Caribbean reefs. Proceedings of the Royal Society B 268: 1-7.

363 Levitan DR, Edmunds PJ, Levitan KE. 2014. What makes a species common? No evidence

364 of density-dependent recruitment or mortality of the sea urchin Diadema antillarum after the

365 1983-1984 mass mortality. Oecologia 175: 117-128.

366 Ling, SD, Johnson CR, Ridgway K, Hobday AJ, Haddon M. 2009. Climate-driven range

367 extension of a sea urchin: inferring future trends by analysis of recent population dynamics.

368 Global Change Biology 15: 719-731.

369 Logan A. 2013. Coral reefs of the Cayman Islands. In: Sheppard C, ed. Coral Reefs of the

370 United Kingdom Overseas Territories (Coral Reefs of the World). Berlin: Springer-Verlag, 61-

37168.

372

373 NOAA Coral Reef Watch. 2000. Data from February, May, and August 2010-2013.

374 http://coralreefwatch.noaa.gov/satellite/vs/index.php

375

376

Miller MW, Kramer KL, Williams SM, Johnston L., Szmant AM. 2009. Assessment of current rates of Diadema antillarum larval settlement. Coral Reefs 28: 511-515.

378

379

McCoy CMR, Dromard CR, Turner JR. 2009. An evaluation of Grand Cayman MPA

380 performance: a comparative study of coral reef fish communities. Proceedings of the $62^{\text {nd }}$ Gulf 381 and Caribbean Fisheries Institute 62: 337-345. 
382 Nguyen KDT, Morley SA, Lai C-H, Clark MS, Tan KS, Bates AE, Peck LS. 2011. Upper

383 temperature limits of tropical marine ectotherms: global warming implications. PLoS One 6 :

384 e29340.

385 Przeslawski R, Ahyong S, Byrne M, Wörheides G, Hutchings P. 2008. Beyond corals and 386 fish: the effects of climate change on noncoral benthic invertebrates of tropical reefs. Global

387 Change Biology 14: 2773-2795.

388

389

390

391

392

Rogers A, Blanchard JL, Mumby PJ. 2014. Vulnerability of coral reef fisheries to a loss of structural complexity. Current Biology 24: 1000-1005.

Sewell MA, Young CM. 1999. Temperature limits to fertilization and early development in the tropical sea urchin Echinometra lucunter. Journal of Experimental Marine Biology and Ecology 236: 291-305.

\section{Tolleter D, Seneca FO, DeNofrio JC, Krediet CJ, Palumbi SR, Pringle JR, Grossman AR.}

2013. Coral bleaching independent of photosynthetic activity. Current Biology 23: 1782-1786.

Ubaldo JP, Uy FA, Dy DT. 2007. Temperature tolerance of some species of Philippine intertidal echinoderms. Philippine Scientist 44: 105-119.

.




\section{1}

Sea urchins in field sites.

Sea urchins in field sites. A) Echinometra lucunter. B) Diadema antillarum. 
PeerJ Reviewing Manuscript

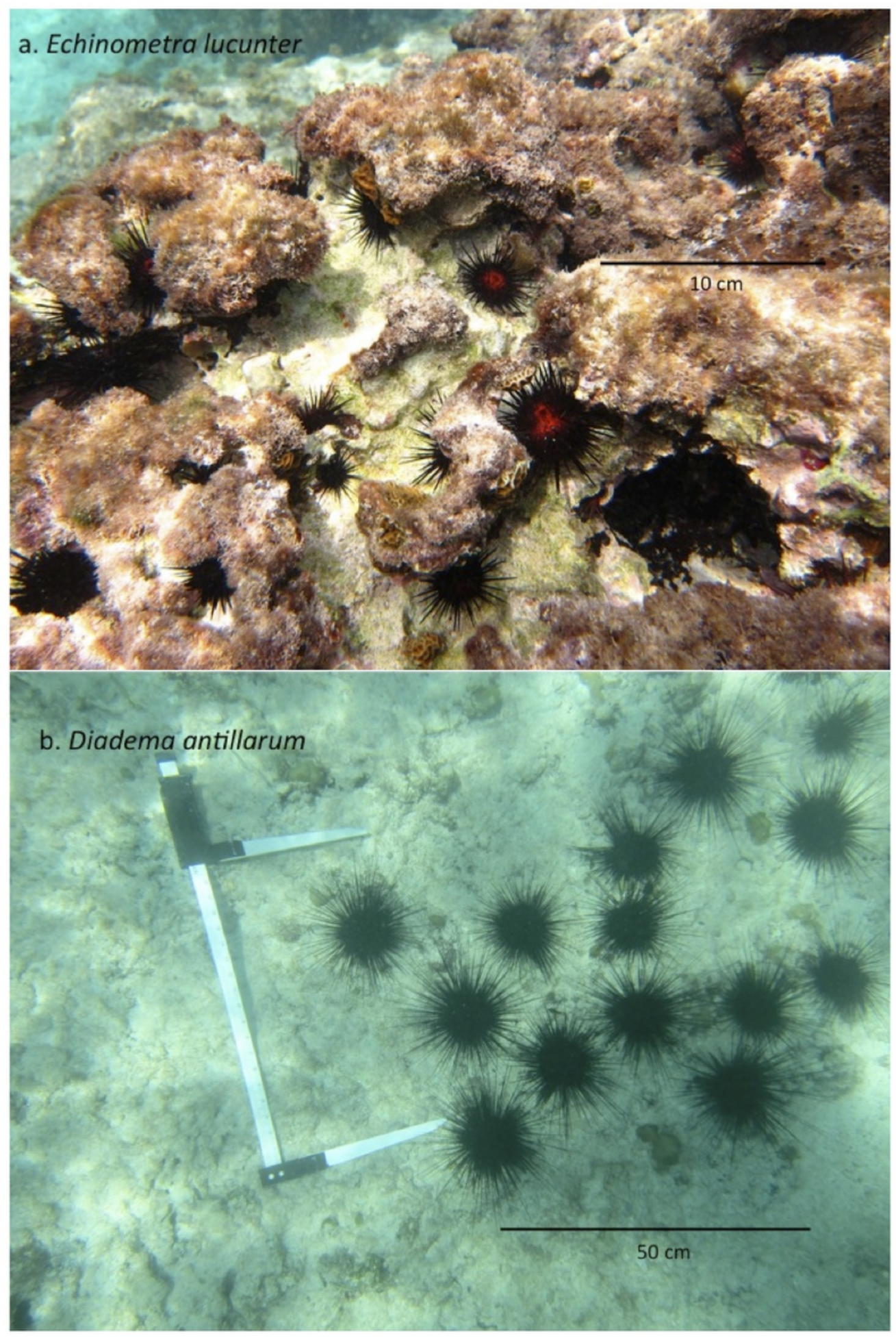




\section{2}

Sea temperatures.

Sea temperatures reported in this study compared to reef sea temperatures of the Cayman Islands in February, May, and August, 2010-2013, reported by NOAA Coral Reef Watch. Bars represent means with vertical lines representing 1 SEM. Sample sizes are indicated above bars. The difference between mean temperature in this study and that of NOAA data are indicated by a $\Delta$ below the $x$-axis. A two-way ANOVA revealed that temperatures increased with month $(p<0.0001)$ in both data sets and that the NOAA data (recorded at night) were significantly lower than the data from the present study, which were recorded during the day $(p<0.0001)$. There was no interaction of temperature and study $(p=0.541)$.

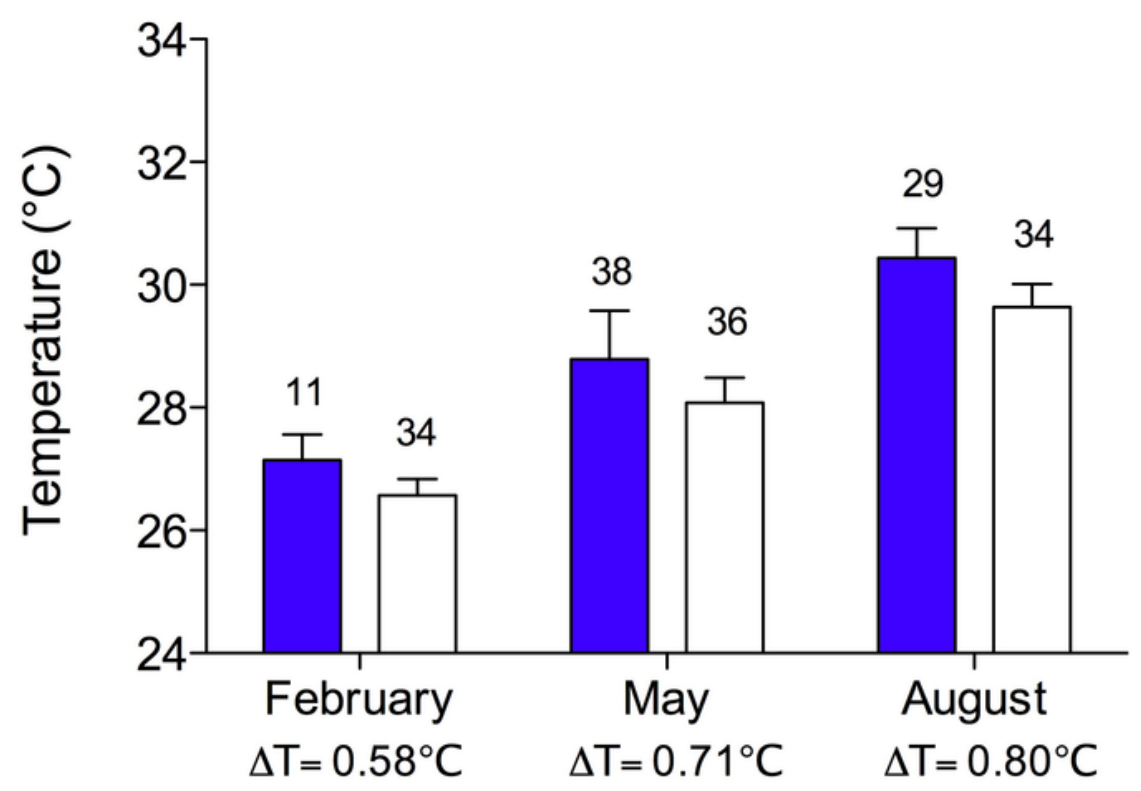

Collection Months 


\section{3}

Temperature at the loss of righting $\left(T_{\text {LoR }}\right)$

Temperature at the loss of righting $\left(\mathrm{T}_{\text {LoR }}\right)$ of $D$. antillarum and $E$. lucunter at different collection temperatures. The symbols represent mean $\mathbf{T}_{\text {LoR }}$ with vertical lines representing 1 SEM. Sample sizes are indicated above or below the symbol. The dotted line represents the line of equality, $\mathbf{T}_{\text {LoR }}=$ sea temperature. The thermal safety margin is the distance between the fitted lines and the line of equality. The main effects of species $\left(F_{1,46}=29.51, p<0.0001\right)$ and collection temperature $\left(F_{2,46}=48.17, p<0.0001\right)$ were significant predictors of $T_{\text {LoR }}$ but their interaction was not $\left(F_{2,46}=2.189, p=0.12\right)$.

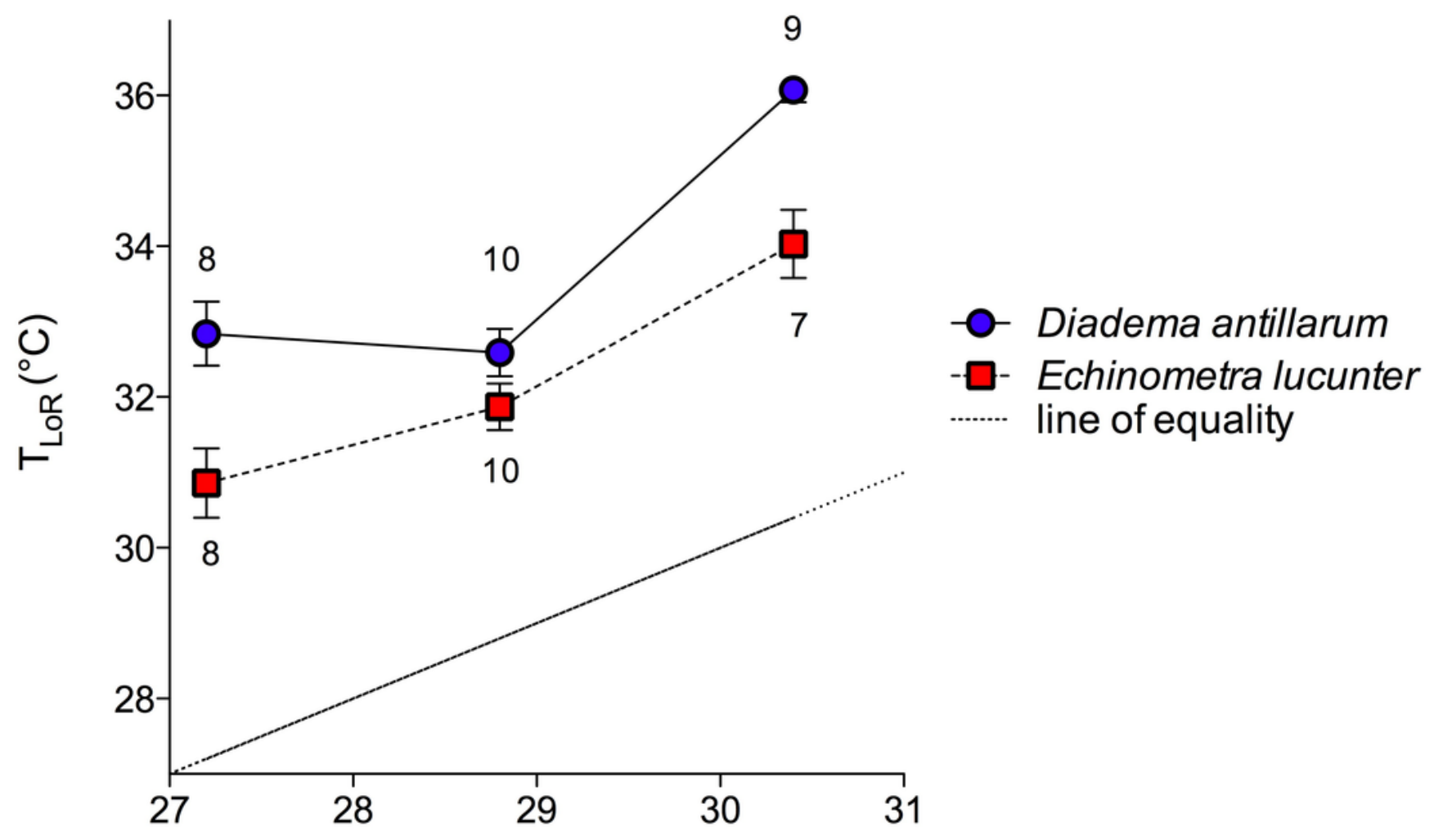

Collection temperature $\left({ }^{\circ} \mathrm{C}\right)$ 


\section{4}

Mean righting times $\left( \pm\right.$ SEM) at increasing experimental temperatures (below $T_{\text {LoR }}$ )

Mean righting times ( \pm SEM) at increasing experimental temperatures (below $T_{\text {LoR }}$ ) of $A$ ) Diadema and B) Echinometra collected during the winter, spring, and summer. For clarity, the data are displayed in bins of experimental temperatures of $1.9^{\circ} \mathrm{C}$. Species $(p<0.0001)$ and collection temperature $(p=0.025)$ significantly affected righting time but the temperatures at which the sea urchins were tested did not $(p=0.561)$. Model: $F_{3,431}=56.58$; $p<0.0001 ; R^{2}=0.28$. Note that the $y$-axes are scaled differently. 
A.
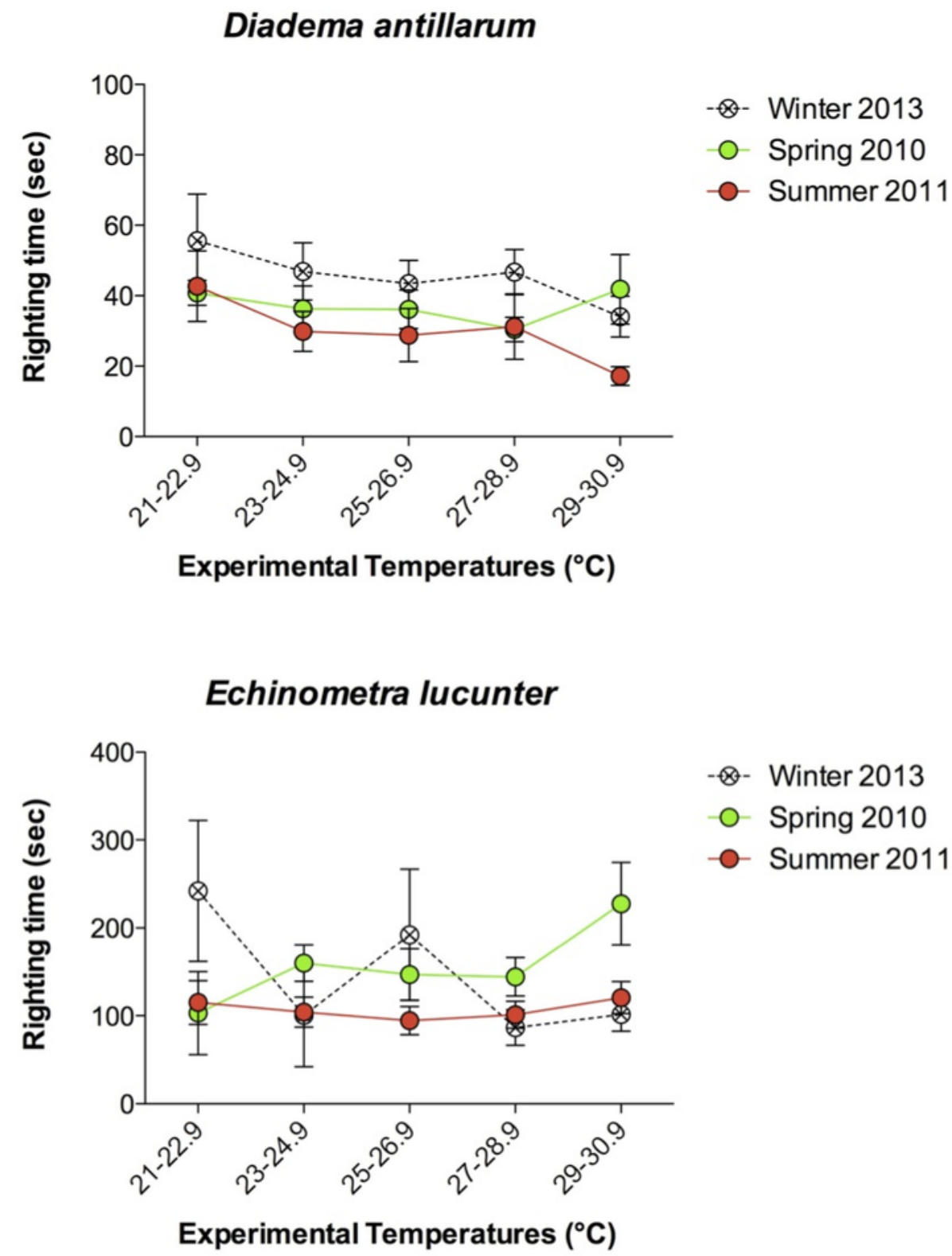

- Winter 2013

O- Spring 2010

o- Summer 2011 
5

Mean ratio of longest spine per test diameter

Mean ratio of longest spine per test diameter $( \pm$ SEM) of Diadema and Echinometra $(t=10.74$, $d f=51 ; p<0.0001)$. Sample sizes are indicated above the bars.

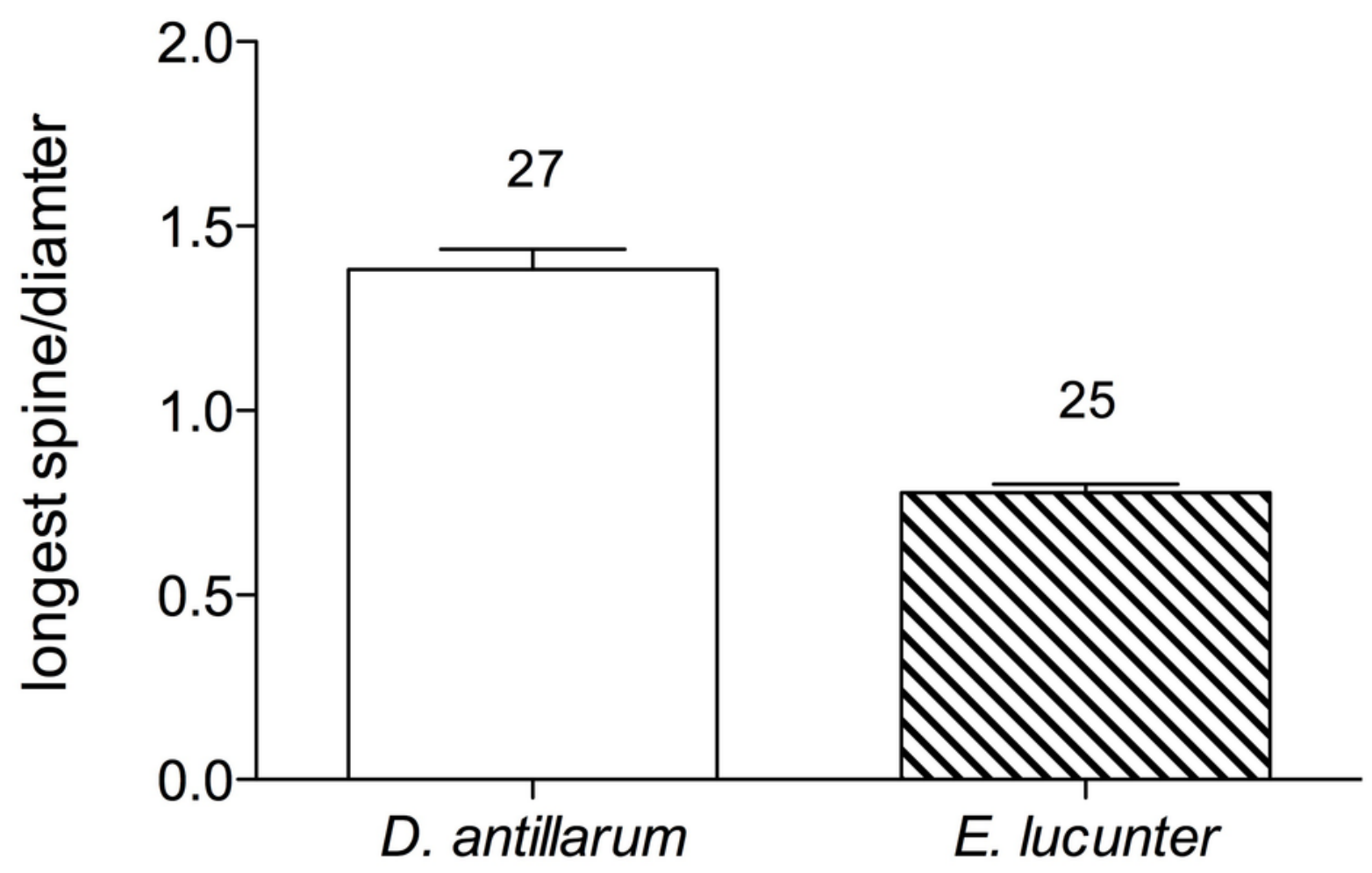


6

$\mathrm{T}_{\text {LoR }}$ as a function of test size

$\mathrm{T}_{\text {LoR }}$ as a function of test size in A) Diadema and B) Echinometra collected in the winter, spring, and summer. None of the slopes is significantly different from 0. Diadema: $p_{\text {winter }}=$ $0.396 ; p_{\text {spring }}=0.528 ; p_{\text {summer }}=0.818$. Echinometra: $p_{\text {winter }}=0.783 ; p_{\text {spring }}=0.689 p_{\text {summer }}=0.10$. Note that the $x$-axes are scaled differently. 


\section{A. \\ Diadema antillarum}

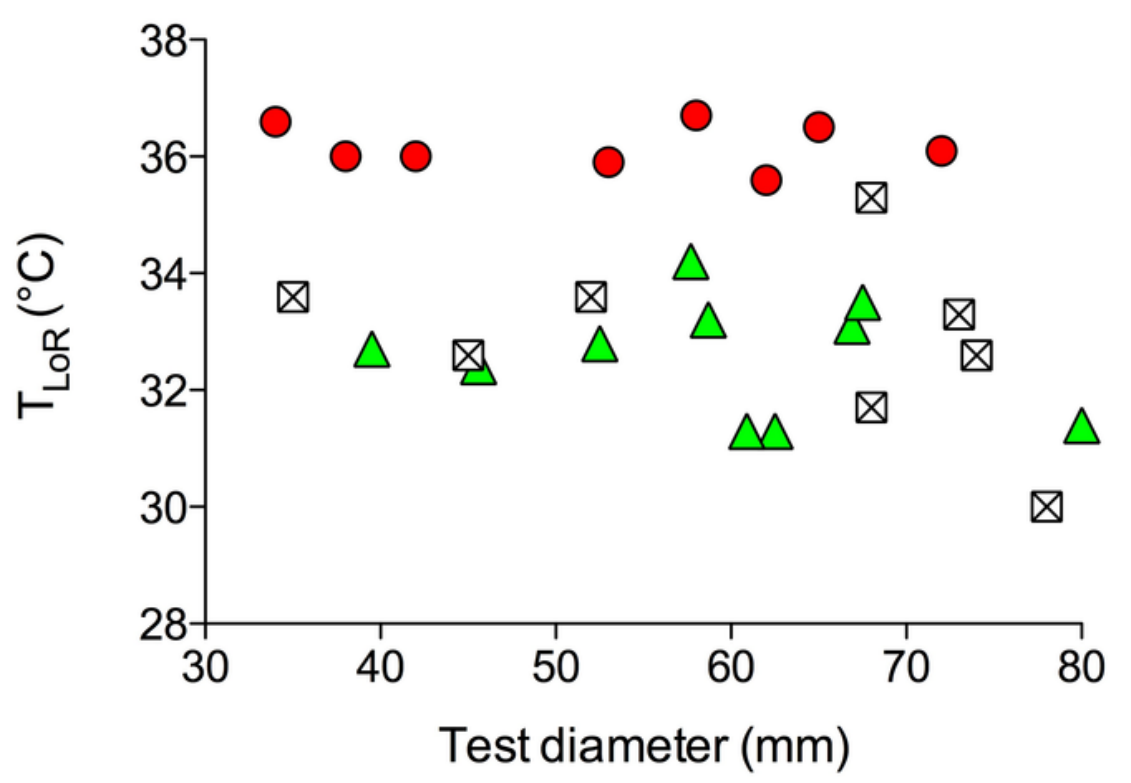

$\otimes \quad$ Winter 2013

$\triangle$ Spring 2010

- Summer 2011

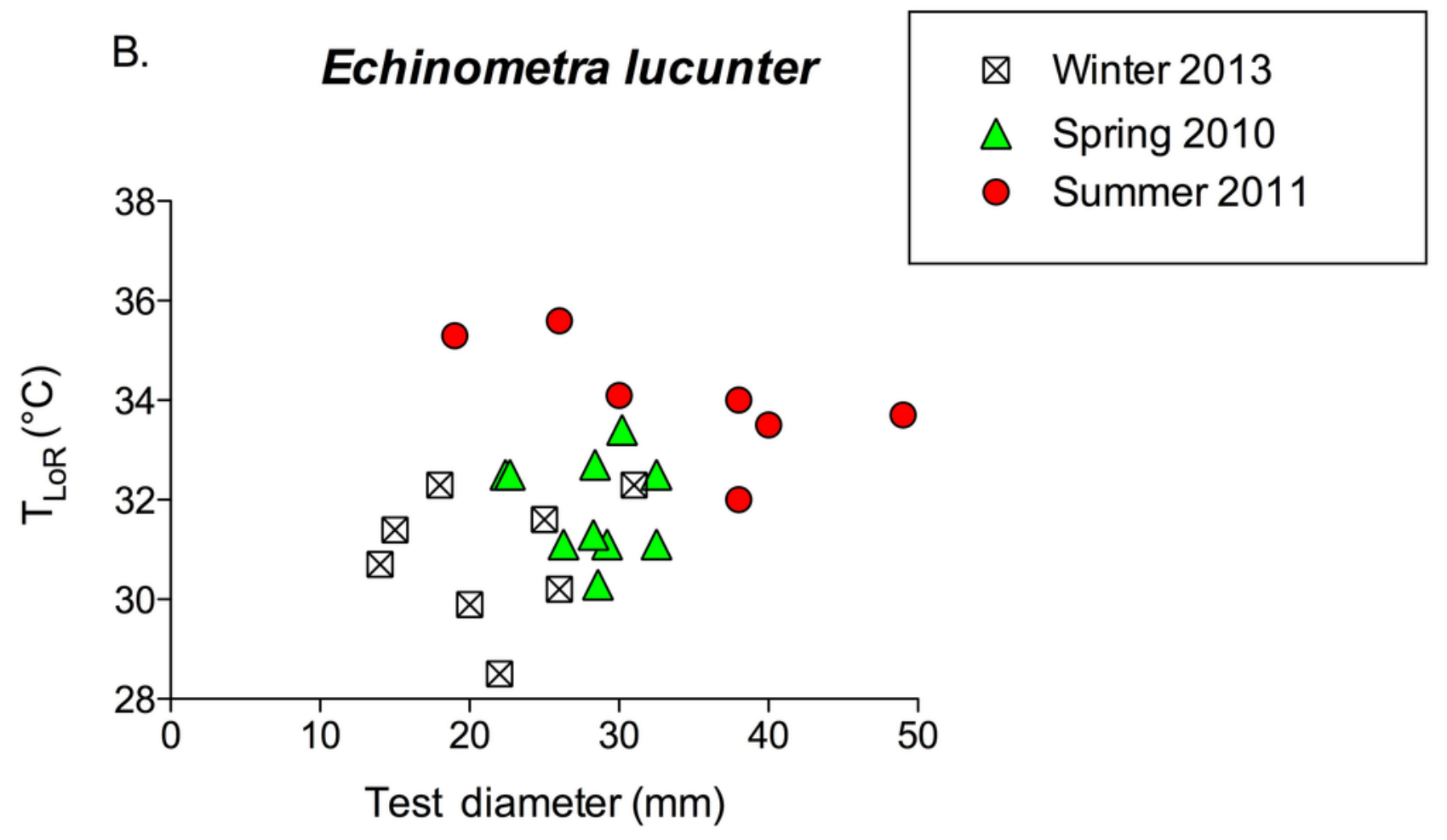




\section{Table $\mathbf{1}$ (on next page)}

Table 1

Difference between mean $T_{\text {LoR }}$ and mean collection temperature (thermal safety margin) for both species. 


\begin{tabular}{|l|l|l|}
\hline & D. antillarum & E. lucunter \\
\hline FEBRUARY & $5.64^{\circ} \mathrm{C}$ & $3.66^{\circ} \mathrm{C}$ \\
\hline MAY & $3.79^{\circ} \mathrm{C}$ & $3.07^{\circ} \mathrm{C}$ \\
\hline AUGUST & $5.67^{\circ} \mathrm{C}$ & $3.63^{\circ} \mathrm{C}$ \\
\hline
\end{tabular}




\section{Table 2 (on next page)}

Table 2

Ranges in $T_{\text {LoR }}$ of both species across the 3 collecting seasons. Numbers in parentheses represent the difference between the highest and lowest $\mathrm{T}_{\text {LoR }}$ for each species. 


\begin{tabular}{|l|l|l|}
\hline & D. antillarum & E. lucunter \\
\hline FEBRUARY & $30.0-35.3^{\circ} \mathrm{C} \mathrm{(5.3)}$ & $29.9-32.3^{\circ} \mathrm{C}(2.4)$ \\
\hline MAY & $31.3-34.2^{\circ} \mathrm{C} \mathrm{(2.9)}$ & $30.3-33.4^{\circ} \mathrm{C}(3.1)$ \\
\hline AUGUST & $35.2-36.7^{\circ} \mathrm{C} \mathrm{(1.5)}$ & $32.0-35.6^{\circ} \mathrm{C} \mathrm{(3.6)}$ \\
\hline
\end{tabular}

